\title{
UCA Acessibilidade: Uma realidade das escolas participantes em Mato Grosso do Sul
}

\author{
Jaqueline S. Vargas ${ }^{1}$, Shirley T. Gobara ${ }^{1}$, Ana G. D. Corrêa ${ }^{2}$, Patrícia A. Oliveira ${ }^{2}$, \\ Gilda A. de Assis ${ }^{2}$, Irene K. Ficheman ${ }^{2}$, Roseli D. Lopes ${ }^{2}$, Marilena Nascimento ${ }^{2}$ \\ ${ }^{1}$ Instituto de Física - Universidade Federal do Mato Grosso do Sul (UFMS) \\ Cidade Universitária - CEP: 79070-900 - Campo Grande - MS - Brasil \\ ${ }^{2}$ Laboratório de Sistemas Integráveis da Escola Politécnica (LSI-EP) - Universidade de \\ São Paulo (USP) - Av. Prof. Luciano Gualberto, travessa 3, nº 158 - CEP: 05508-970 - \\ São Paulo - SP - Brasil \\ jkvargas-ehotmail.com
}

\begin{abstract}
This paper presents the results of a survey conducted in schools that participated in the UCA project in the state of Mato Grosso do Sul whose main objective was to identify the accessibility requirements in educational laptops and adaptation needs in terms of disabled students enrolled in participating schools of UCA project and the schools conditions to receive these students. The results showed that schools serve a significant number of disabled people being identified as the most intellectual deficient and that the adaptation of the laptop is needed for the inclusion of these students. Moreover, schools are not adequately prepared to receive these students.
\end{abstract}

Resumo. Este artigo apresenta os resultados de um levantamento realizado nas escolas que participaram do projeto UCA no estado de Mato Grosso do Sul, cujo objetivo principal foi levantar os requisitos de acessibilidade nos laptops educacionais e as necessidades de adaptação em função dos alunos deficientes matriculados nas escolas participantes do projeto UCA e as condições das escolas para receber esses alunos. Os resultados evidenciaram que as escolas atendem um número significativo de deficientes sendo a maioria identificada como deficiente intelectual e que a adaptação do laptop é necessária para a inclusão desses alunos. Além disso, as escolas ainda não estão adequadamente preparadas para receber esses alunos.

\section{Introdução}

O Projeto UCA (Um Computador por Aluno), desde sua implantação, em 2006, teve como objetivo promover a inclusão digital dos alunos participantes do projeto, distribuindo aos alunos e professores um laptop educacional para realizarem as atividades escolares e extraescolares.

$\mathrm{Na}$ atual sociedade da informação, o uso das tecnologias digitais de informação e comunicação já faz parte do cotidiano dos alunos e, portanto, a inclusão digital é algo inevitável, e as crianças nascidas no século XXI já são consideradas nativas digitais.

A escola como instituição social deve acompanhar e participar do desenvolvimento das novas tecnologias. Neste sentido, as tecnologias da informação e 
comunicação (TIC) estão presentes no ambiente escolar, principalmente, via computador e celulares, e a escola como parte da sociedade também deve passar por este tipo de transformação, ou seja, usar as tecnologias para a melhoria da aprendizagem dos alunos.

A tecnologia também é uma aliada importante na educação inclusiva, tendo em vista que a Educação Inclusiva é um sistema educacional no qual os alunos com deficiência e necessidades educacionais especiais frequentam as mesmas aulas que os alunos sem deficiência, em escolas regulares, tanto públicas quanto privadas, pois a partir da Constituição Federal de 1988 "se torna dever do Estado a garantia de atendimento educacional especializado aos portadores de deficiência, preferencialmente na rede regular de ensino" (Brasil, 1988, p.1). Somente em 1996, a Lei de Diretrizes e Bases da Educação Nacional (LDBN) define claramente o apoio que os alunos deficientes devem receber, ao estabelecer que os professores devem ser capacitados, e que as pessoas com deficiência também têm o direito de receber o auxílio de especialistas, em qualquer nível de ensino.

Uma vez que estamos passando por esse processo de inclusão, é preciso pensar em alternativas para que os alunos com deficiência consigam ser inseridos não só no ambiente escolar, mas também consigam utilizar o computador, que é uma ferramenta potencialmente útil para auxiliar na aprendizagem. Neste sentido, as Tecnologias Assistivas (TA) vêm ao encontro dessas necessidades, pois de acordo com Galvão Filho et al (2009, p. 26):

Tecnologia Assistiva é uma área do conhecimento, de característica interdisciplinar, que engloba produtos, recursos, metodologias, estratégias, práticas e serviços que objetivam promover a funcionalidade, relacionada à atividade e participação de pessoas com deficiência, incapacidades ou mobilidade reduzida, visando sua autonomia, independência, qualidade de vida e inclusão social.

Pensando nessa problemática, o projeto UCA foi implantado, também, na perspectiva de que os laptops educacionais pudessem ser utilizados como instrumentos de promoção desta igualdade de oportunidades, entretanto, o laptop educacional não foi projetado para atender a parcela de alunos com as mais diferentes deficiências. Preocupados em incluir esses alunos, o projeto denominado Tecnologias Assistivas ${ }^{1}$ Livres para Inclusão de Pessoas com Deficiência no Projeto UCA-PROUCA está sendo desenvolvido e tem como objetivo principal levantar as necessidades de adaptação dos laptops educacionais para serem utilizados pelos alunos com deficiência das escolas que participam do PROUCA.

Esse projeto foi proposto para ser desenvolvido em 4 etapas (Correa, et al, 2013a, 2013b). Não necessariamente desenvolvidas nessa ordem de apresentação das etapas, algumas foram realizadas em paralelo.

I) levantamento de requisitos de acessibilidade nos laptops educacionais;

II) mapeamento de tecnologias livres;

\footnotetext{
${ }^{1}$ Uma discussão sobre o significado de tecnologia assistiva encontra-se no artigo "Projeto UCA-Assistiva: mapeamento e avaliação de ferramentas assistivas nos laptops educacionais do PROUCA" (Correa et al, 2013b).
} 
III) adaptações e/ou desenvolvimentos de novas tecnologias;

IV) testes e avaliações das tecnologias adaptadas e/ou desenvolvidas;

Este trabalho é um recorte dessa pesquisa, em que apresentaremos os resultados da investigação da primeira etapa realizada para levantamento de requisitos de acessibilidade nos laptops educacionais desenvolvidas nas escolas participantes do Projeto UCA em Mato Grosso do Sul.

\section{Metodologia da Pesquisa}

Este projeto de pesquisa está sendo conduzido por uma equipe multidisciplinar de profissionais do Laboratório de Sistemas Integráveis (LSI) da Escola Politécnica da Universidade de São Paulo (LSI-EPUSP), da Universidade Federal do Mato Grosso do Sul (UFMS), da Universidade Federal do Amapá (UNIFAP).

Neste artigo, apresentaremos o desenvolvimento da primeira etapa do projeto em que foram levantadas, nas escolas participantes do projeto UCA, as necessidades e requisitos de acessibilidade dos laptops educacionais. $\mathrm{O}$ objetivo principal foi levantar os requisitos de acessibilidade nos laptops educacionais, os tipos de deficiências e as necessidades de adaptação em função dos alunos deficientes matriculados nas escolas participantes do projeto UCA e as condições das escolas para receber esses alunos.

A segunda etapa foi o mapeamento das tecnologias assistivas livres, na qual foi feito um levantamento das tecnologias existentes que poderiam ser instaladas no laptop educacional. Os resultados da etapa II, que trata do levantamento e mapeamento das tecnologias livres de acessibilidade existentes e uma análise sobre a viabilidade de utilização, encontram-se no artigo "Projeto UCA-Assistiva: mapeamento e avaliação de ferramentas assistivas nos laptops educacionais do PROUCA" (Correa et al, 2013b).

Esta pesquisa é qualitativa do tipo exploratório, uma vez que propusemos estudar a realidade das escolas (para o atendimento aos alunos deficientes) que participam do Projeto UCA, além de levantar as tecnologias existentes, e as informações dos alunos, pais, professores e gestores sobre o uso do laptop pelos alunos na escola, em casa e em outros ambientes.

Os instrumentos de pesquisa foram questionários semiestruturados que foram aplicados aos gestores das escolas e questionários estruturados aos professores, alunos e pais ou responsáveis pelos alunos.

\subsection{Etapa I - Levantamento de requisitos de acessibilidade nos laptops educacionais}

Esta etapa foi desenvolvida por todas as equipes do projeto, porém cada uma das equipes investigou a realidade de suas escolas. Dessa maneira, nossa equipe da UFMS, realizou o levantamento nas escolas participantes do Projeto UCA em Mato Grosso do Sul no ano de 2012 (objeto desse artigo).

Primeiramente, foi realizada uma pesquisa por telefone com os gestores das escolas porque as escolas que participam do PROUCA em Mato Grosso do Sul são distantes da capital, onde a equipe da UFMS encontra-se localizada, e para viabilizar custos, tempo e evitar muitas viagens. 
No total, foram 18 escolas investigadas, das quais foram entrevistados coordenadores, diretores e secretários. Inicialmente, levantamos as escolas que possuíam alunos com deficiência, além de investigar a situação da escola no que diz respeito à inclusão.

Depois do levantamento das deficiências e das condições das escolas com relação às adaptações para receber os alunos com deficiência, foram escolhidas duas escolas, nas quais foram aplicados questionários para os professores, alunos e pais ou responsáveis dos alunos, com o objetivo de levantar a realidade vivida pela escola, pelos alunos e pelos pais, com relação à inclusão digital. Foram escolhidas as duas escolas quem tinham mais alunos deficientes.

\subsection{Etapa II - Mapeamento de tecnologias assistivas livres}

Esta etapa foi desenvolvida pela equipe do LSI-EPUSP. Foi feito um mapeamento das tecnologias de hardware e software livres existentes. Foram selecionadas as tecnologias que estavam prontas para serem instaladas e testadas nos laptops educacionais (Correa et al, 2013a). A nossa equipe da UFMS colaborou apenas na criação de um manual para auxiliar nas instalações dos softwares.

\section{Resultados e discussão}

Inicialmente, entrevistamos os 18 gestores das escolas que participam do PROUCA no MS. Com o resultado das informações obtidas nessas entrevistas, escolhemos duas escolas que apresentaram os maiores índices de alunos com deficiência matriculados, de acordo com a metodologia adotada pela equipe de pesquisadores.

As duas escolas escolhidas totalizaram 400 alunos matriculados e 37 professores. Os questionários dos professores e dos alunos foram aplicados na escola pela equipe de pesquisadores da UFMS. Os questionários dos pais ficaram sob a responsabilidade da direção (coordenadora) da escola.

Foram analisados 37 questionários de professores, 62 de alunos e somente 28 questionários dos pais ou responsáveis. $\mathrm{O}$ número de pais foi menor porque uma das escolas, a mais numerosa, em que foram aplicados os questionários, não nos devolveu as respostas dos pais, assim ficamos com os dados de apenas uma das escolas.

Em conjunto com todas as equipes, foi estabelecido que os alunos que responderiam os questionários seriam preferencialmente alunos das $4^{\mathrm{a}}, 5^{\mathrm{a}}, 6^{\mathrm{a}}$ e $7^{\mathrm{a}}$ séries, porém fizemos também com os alunos na $8^{\mathrm{a}}$ série, pois existiam alunos com deficiência nessa série.

Para a identificação das escolas adotamos a letra 'E' e um número como índice para indicar diferentes escolas, por exemplo, escola 3 tem a representação $E_{3}$. Da mesma maneira, identificamos os sujeitos da pesquisa: os professores letra $\mathrm{P}$, os alunos $\mathrm{A}$, gestores letra $\mathrm{G}$ e pais ou responsáveis letra $\mathrm{R}$, todos acompanhados pelos números de representação de sua respectiva escola.

\subsection{Aplicação dos questionários e realização das entrevistas}

\subsubsection{Entrevista com os gestores (Etapa I)}

Primeiramente, realizamos as entrevistas com os 18 gestores das escolas participantes. 
O objetivo dessas entrevistas foi levantar o número de alunos com deficiências nessas escolas, se os alunos, de maneira geral (com deficiência ou não), utilizam o computador no dia a dia, se a escola usava alguma tecnologia assistiva e se ela estava preparada para receber alunos com deficiência.

Com as entrevistas, levantamos que várias escolas possuíam e ainda possuem alunos com deficiência, porém ainda não estão preparadas para receber esses alunos de forma adequada. As escolas, em geral, não possuem adaptações para a acessibilidade, como, por exemplo, banheiro adaptado ou rampa de acesso, principalmente nas escolas da área rural. Um aspecto importante a destacar é que a maioria dos entrevistados manifesta uma preocupação em receber esses alunos de forma adequada, isto é, que as escolas podem ser melhor preparadas para recebê-los, como podemos ver na fala de um dos diretores:

$\mathrm{G}_{12}$ : "Seria interessante integrar um curso né. Junto com a professora que atende a sala de recursos, juntamente com os demais professores. Porque aqui nós temos séries iniciais. Então, daria pra fazer um curso voltado pra educação especial, até pra atender melhor esses alunos."

Porém, quando perguntamos sobre as tecnologias existentes na escola para que os alunos com deficiência pudessem usar o computador e/ou o laptop, muitos desconheciam e outros afirmaram que não tinham tempo para aprender. Em algumas escolas, essa tarefa é atribuída ao professor da sala de recursos (sala adaptada para os alunos com deficiência) que, em geral, é um professor especializado, contratado para atender os alunos com deficiência.

Dos gestores entrevistados, apenas o $\mathrm{G}_{4}$ soube informar as tecnologias que a escola possuía para atender os alunos cegos e de baixa visão, que são os ampliadores de tela e as lupas digitais, os outros 17 não conheciam ou não sabiam se a escola possuía, pois o responsável é o professor da sala de recursos.

Com relação aos laptops educacionais, a queixa maior foi que é possível realizar tarefas para os alunos e talvez até adaptá-los aos alunos com deficiência, porém se as atividades precisarem de internet, eles não acham uma boa ideia, já que a conexão da internet nas cidades em que essas escolas estão localizadas não é suficiente para atender todos os computadores.

Alguns gestores informaram que os alunos com deficiência não utilizavam o laptop porque ele não tinha as adaptações necessárias para atender as dificuldades desses alunos. Por exemplo, o gestor $\mathrm{G}_{9}$ disse que existe um aluno que possui deficiência motora e, enquanto os outros alunos fazem a tarefa no laptop educacional, ele faz outra atividade no papel, porque ele não consegue controlar o cursor na tela.

Levantamos, também, o número de alunos com deficiência das escolas participantes do UCA em Mato Grosso do Sul, os quais foram sintetizados na Tabela 1.

Tabela 1 - Alunos com deficiência nas escolas participantes do UCA/ MS (dados de 2012)

\begin{tabular}{|c|c|}
\hline Tipo de Deficiência & Quantidade de matriculados \\
\hline Física & 12 \\
\hline Visual & 6 \\
\hline Auditiva & 5 \\
\hline
\end{tabular}




\begin{tabular}{|c|c|}
\hline Mental & 7 \\
\hline Intelectual & 52 \\
\hline Síndrome de Down & 1 \\
\hline Distúrbios de Aprendizagem & 14 \\
\hline Sem laudo & 21 \\
\hline Total & 118 \\
\hline
\end{tabular}

Considerando-se que esse resultado é relativo às 18 escolas que participaram do projeto UCA, esse número é relevante e aponta para o problema ainda pouco explorado que é a inclusão digital desses alunos, em particular no âmbito do projeto UCA, pois a maioria não conseguia usar o laptop, o que reforça a importância de realizar um projeto cujo foco de investigação é a acessibilidade e as tecnologias assistivas adaptáveis ao laptop educacional e justifica-se o desenvolvimento e a continuidade do projeto no sentido de buscar a adaptação dos laptops para atender esse público.

Os dados da tabela 1 foram usados apenas para identificar as deficiências e para mostrar que, embora esses alunos estejam incluídos socialmente, eles continuam desassistidos funcionalmente, do ponto de vista da igualdade de condições em relação aos alunos não deficientes.

Após esse levantamento e a realização das entrevistas com os gestores, selecionamos duas escolas $\left(\mathrm{E}_{4}\right.$ e $\left.\mathrm{E}_{16}\right)$, aquelas que apresentaram os maiores números de alunos com deficiência, totalizando 38 alunos, para a aplicação dos questionários com os alunos, pais e professores. Passaremos a apresentar os dados obtidos nas respostas dos questionários.

\subsubsection{Questionários dos professores}

O questionário aplicado aos professores teve como objetivo levantar as informações para obter um panorama geral da área de atuação; da experiência, preparação e a motivação para o uso da Tecnologia da Informação; da visão deles sobre as dificuldades da logística para o Projeto UCA e sobre a demanda das crianças com necessidades especiais.

Os resultados mostraram que, em ambas as escolas, durante a nossa visita, os professores estavam utilizando os laptops educacionais para a realização das atividades em sala de aula com todos os alunos e que eles demostraram possuir muita facilidade para manusear o computador e suas ferramentas.

Os professores disseram que a maioria dos alunos possui computador em casa, porém a internet ainda não é acessível a todos, isso porque os municípios não possuem uma rede que consiga atender a todos os moradores, assim a internet continua sendo um problema para a utilização do computador, pois, sem a internet, o computador torna-se um vídeo game para os alunos, pois eles só querem jogar.

No que diz respeito aos alunos com deficiência, na escola $E_{4}$, vários professores possuem alunos com deficiência em suas turmas, porém eles são acompanhados por especialistas da educação especial. E, enquanto os alunos sem deficiência estão realizando atividades no laptop, os alunos com deficiência são atendidos pelos acompanhantes, porém, dependendo do grau da deficiência, esses alunos acabam fazendo uma tarefa diferenciada, sem o laptop. 
Com relação ao uso do laptop como uma ferramenta de auxílio à aprendizagem dos alunos foi possível perceber que o professor se diz motivado para receber novos desafios dentro do ambiente atual da escola, porém ele ainda continua bastante limitado na exploração das potencialidades dessa tecnologia. As atividades sugeridas aos alunos pelos professores são, em geral, buscas de informação na internet, atividades de digitação e ilustração usando os aplicativos do laptop ou jogos que exploram basicamente a memória dos alunos.

\subsubsection{Questionário dos alunos}

A aplicação do questionário aos alunos teve como objetivo geral mapear as oportunidades de acesso às tecnologias da informação que os alunos (com e sem deficiência) possuem nos diversos ambientes da comunidade e no domicílio e teve como objetivo específico determinar o quanto a criança está motivada para as atividades extra escolares com o uso do computador .

Os dados obtidos pelos questionários dos alunos mostraram que a grande maioria possui computador em casa, o que confirma a informação dada pelos professores, e gostam de utilizar o computador no dia a dia. Porém, as atividades que eles realizam não estão diretamente ligadas às tarefas escolares. Poucos alunos possuem internet em casa, pois como foi dito pelos professores, a internet é de difícil acesso, uma vez que os municípios não possuem uma rede de grande acesso.

Os alunos que, de alguma maneira, utilizam a internet em casa ou na Lan House, acabam usando apenas para jogar ou acessar as redes sociais. Os alunos demonstraram bastante interesse em conhecer novos recursos para usar o computador, porém eles ainda não associam o computador como uma ferramenta para as tarefas escolares.

\subsubsection{Questionário dos pais}

Os questionários aplicados aos pais tiveram como objetivo levantar as condições físicas e motivacionais da família para as questões da tecnologia da informação.

Foi possível perceber pelas respostas dos questionários devolvidos que alguns pais têm baixo grau de escolarização e não usam o computador e nem a internet, talvez por falta de conhecimento ou de oportunidade, uma vez que vários possuem $\mathrm{o}$ computador em casa.

Já os pais que utilizam o computador e acessam a internet, mesmo tendo o conhecimento, não ajudam seus filhos na utilização do mesmo, como podemos observar em uma das respostas do pai $\mathrm{R}_{17}$ : "Não tem, ela é bem esperta tem facilidade pra aprender." Outros pais, mesmo tendo computador em casa não sabiam das dificuldades dos filhos para utilizar o computador. Entretanto, os professores revelaram conhecer essa realidade, como podemos ver na fala de um dos professores: $\mathrm{P}_{2}$ : "A família não faz. um acompanhamento com os filhos".

Dos 28 pais que responderam o questionário, apenas 12 responderam a questão sobre a utilização do laptop educacional pelos seus filhos. E, das respostas obtidas, a maioria aponta o problema da conexão com a internet. Com relação às atividades na escola, não apareceu nenhuma resposta.

Os resultados mostram que os alunos que usam a internet, seja em casa ou em Lan House, não usam para o estudo. Portanto, uma ferramenta que poderia ser aliada ao 
estudo, só serve para o entretimento e diversão. Mesmo não acompanhando os filhos no uso do computador, os pais acham importante aprender a utilizar o computador.

\subsection{Etapa II - Mapeamento das tecnologias assistivas}

O objetivo dessa etapa foi mapear as tecnologias assistivas livres. O estudo para o mapeamento das tecnologias de hardware e software livres foi feito por meio de uma pesquisa bibliográfica, na internet e entrevistas com representantes/fornecedores de tecnologias nacionais e internacionais. Após a análise das informações dessas três fontes, foram selecionadas as tecnologias que estavam prontas e que eram compatíveis para serem instaladas nos laptops educacionais.

O mapeamento foi realizado pela equipe 1 , as outras equipes não participaram dessa etapa da pesquisa. Após a seleção dos hardwares e softwares, foi preciso fazer outra seleção, pois era preciso conhecer os programas que poderiam ser instalados no laptop educacional, uma vez que não são todos os programas que o laptop aceita.

No Laptop, foi instalado o Sistema Operacional: Linux Acessível, que é um sistema que possui várias ferramentas de acessibilidade, como, por exemplo, leitor de tela, ampliação e contraste. Além dessas, outros softwares compatíveis foram instalados: Eviacam, Teclado Virtual XVKBD, Cheese e o Tuxpain e um dicionário para os alunos com surdez.

Uma discussão detalhada dessa etapa da pesquisa encontra-se no artigo "Tecnologias Assistivas Livres para Inclusão de Alunos com Deficiência no Projeto UCA" (Correa et al, 2013a), trabalho apresentado no II Congresso Brasileiro de Informática na Educação (CBIE 2013) Workshops (WCBIE 2013), cujo objetivo foi apresentar um análise sobre a viabilidade do uso das ferramentas de acessibilidade nos laptops educacionais no âmbito do projeto UCA.

Após a seleção das ferramentas de acessibilidade, foi criado um manual de instalação para que todas as equipes pudessem instalar os programas nos laptops e as ferramentas que seriam testadas. Além de um manual de instalação, também foi criado um manual de manuseio do equipamento e dos recursos de acessibilidade instalados no laptop UCA-Acessível. Isso facilitou muito o trabalho de instalação e o entendimento para o uso das ferramentas. As outras equipes puderam opinar e ajudar na criação desses manuais.

As próximas etapas do projeto estão justamente relacionadas às testagens dessas ferramentas. Verificar quais dessas ferramentas são passíveis de serem utilizadas pelos alunos como ferramentas auxiliares nas atividades educativas com os alunos deficientes. Os resultados dessa etapa, que está ainda em andamento, serão discutidos e apresentados numa outra oportunidade.

\section{Considerações Finais}

Com esta pesquisa foi possível perceber a importância que o computador está adquirindo no cotidiano das pessoas, pois a maioria que respondeu o questionário (professor, aluno e pais) já teve ou tem acesso ao computador. Alguns pais não utilizam por falta de conhecimento, porém eles acham que os filhos devem usar, pois eles acreditam que é importante saber usar esse recurso. Além disso, os pais não conseguem 
ou acham que não precisam acompanhar seus filhos nas atividades escolares ou quando eles utilizam o computador em outras atividades.

Mas, mesmo que pareça importante a utilização do computador, esse "usar", ainda não está relacionado com o "aprender", pois os alunos usam para diversão e entretenimento e os professores ainda não estão habituados a usar o computador e a internet como aliados para melhorar o aprendizado.

Com relação ao laptop educacional, o grande problema manifestado pelos professores das escolas que participam do Projeto UCA é o acesso à internet, pois a rede disponibilizada para a escola não é suficiente para que os professores consigam trabalhar com todos os seus alunos conectados. Por causa desse problema, alguns professores manifestaram uma aversão à utilização do laptop, porque as aulas, em geral, são preparadas somente para serem realizadas usando a internet e nem sempre ela funciona, e a aula preparada pelo professor acaba não sendo realizada e os alunos, também, ficam decepcionados. Esse comportamento evidencia outro problema, que já foi apontado em outra pesquisa desenvolvida por Gobara e Camilotti (2013), relacionado às dificuldades dos professores para explorar outras possibilidades de uso que o laptop oferece e justificam a não utilização do laptop educacional pela dificuldade ou falta de condições para acessar a internet.

De ponto de vista da inclusão digital para alunos deficientes nas escolas participantes do projeto UCA, verificamos que é necessária a adaptação do laptop educacional, pois encontramos situações em que os alunos sem deficiências faziam atividades no laptop educacional, enquanto os alunos com deficiência realizavam outras atividades.

É possível perceber, também, que mesmo com as leis favorecendo o processo de inclusão, as escolas não estão adaptadas suficientemente e os professores ainda não são capacitados para receber os alunos com deficiência, assim, o trabalho de inclusão ainda está limitado apenas à pessoa que acompanha esse aluno. E quando se trata de tecnologias assistivas, há uma carência ainda maior, pois algumas escolas até possuem algumas ferramentas de acessibilidade, mas por falta de capacitação ou até mesmo conhecimento, estas não são utilizadas e quem sai prejudicado é o próprio aluno deficiente, pois, de certa forma, ele continua excluído porque aumenta a sua defasagem em relação aos demais alunos em termos de aprendizagem.

É preciso, portanto, pensar em como utilizar essas ferramentas, e para que isso aconteça não basta ter as ferramentas disponíveis aos alunos, é necessário capacitar os professores (Gobara, 2012) e as pessoas que acompanham os alunos com deficiência, além é claro de conscientizar os pais, pois também ficou evidente nas respostas dos professores, que os pais deixam os alunos nas escolas e depositam toda a responsabilidade à escola e muitas vezes não sabem o que acontece com seu filho. Cada pessoa que participa desse processo de inclusão deve ter consciência do seu papel, pois se ele não o tem, a inclusão, de fato, não acontece.

De acordo com Kenski (2007), “em um momento caracterizado por mudanças velozes, as pessoas procuram na educação escolar a garantia de formação que lhes possibilite o domínio de conhecimentos e qualidade de vida". E é isso que os alunos com deficiência querem, aprender da mesma maneira que alunos sem deficiência e com 
a mesma oportunidade de vida dos seus colegas, ou seja, poder usufruir das facilidades proporcionadas pela tecnologia, em particular do computador.

\section{Referências}

Brasil. Constituição da República Federativa do Brasil de 1988. Disponível em:< http://www.planalto.gov.br/ccivil_03/constituicao/constitui\%C3\%A7ao.htm>.

Acesso em: jan. 2013.

Brasil, Ministério da Educação. Lei de Diretrizes e Bases da Educação Nacional. LDB 9.394, de 20 de dezembro de 1996. Disponível em: <http://www.planalto.gov.br/ccivil_03/LEIS/L9394.htm>. Acesso em jan. 2013

Brasil. Ministério da Educação. Secretaria de Educação Média e Tecnológica. Parâmetros curriculares nacionais: ensino médio. Brasília: MEC/SEMTEC, 2000. Disponível em: <http://portal.mec.gov.br/seb/arquivos/pdf/blegais.pdf>. Acesso em: out. 2013

Corrêa, A. G., Oliveira, P. A., Assis, G.A., Ficheman, I. K., Nascimento, M., Gobara, S. T., Araújo, E. G., Lopes ,R. D., Tecnologias Assistivas Livres para Inclusão de Alunos com Deficiência no Projeto UCA in Anais do $23^{\circ}$ Simpósio Brasileiro de Informática na Educação (SBIE 2013), São Paulo. (a)

Corrêa, A. G., Oliveira, P. A., Assis, G.A., Ficheman, I. K., Nascimento, M., Gobara, S. T., Araújo, E. G., Lopes, R. D., Projeto UCA-Assistiva: mapeamento e avaliação de ferramentas assistivas nos laptops educacionais do PROUCA, RENOTE-Novas Tecnologias na Educação, v. 11, n. 3, 2013. (b)

Gobara, S. T. e Camilotti, D. C., Continued Education to Integrate the Educational Laptop: Reflections on Educational Practice Change, Creative Education, Vol.4, No.10A, 61-71, 2013.

Gobara, S. T. Formação continuada para o uso das Tecnologias de Informação e Comunicação, Dialogia, São Paulo, n. 16, p. 23-39, 2012.

Kenski, V. M. Educação e Tecnologias: O novo ritmo da informação. Campinas, SP, Papirus, 2007.

Cook e Hussey. Assistive Tecnologies: Principles and Pratice, Mosby. Year Book, USA-Missouri, 1995.

Galvão Filho, T. A. et al. Conceituação e estudo de normas. In: BRASIL, Tecnologia Assistiva. Brasília: CAT/SEDH/PR, 2009, p. 13-39. Disponível em: <http://www.pessoacomdeficiencia.gov.br/app/sites/default/files/publicacoes/livrotecnologia-assistiva.pdf> Acesso em 05 dez. 2013. 